\title{
Sentido y Color de Concierto barroco
}

The tastes of the duke were peculiar. He had a fine eye for colors and effects. He disregarded the decora of mere fashion. His plans were bold and fiery, and his conceptions glowed with barbaric lustre. There are some who would have thought him mad. His followers felt that he was not. It was necessary to hear and touch him to be sure that he was not. (Edgar Allan Poe, The Masque of the Red Death.)

En una conversación reciente que sostuve con Alejo Carpentier el novelista cubano declaró que su último libro Concierto barroco es " "... una 'Novelle' en el sentido alemán de la palabra... aun siendo pequeña la considero como una especie Summa Theologica de mi arte por contener todos los mecanismos del 'barroquismo' simultáneamente". ${ }^{1}$ Dado el lugar prominente en que el autor sitúa esta novela dentro de su obra artística, es importante mostrar en un breve examen cuáles son algunos de estos mecanismos "barrocos" y como se ubican dentro del contexto de la producción literaria carpenteriana.

Desde un principio es fácil advertir que Concierto barroco es una historia elaborada sobre sistemas cromáticos de distintos matices, simbólicos de cualidades determinadas, en una culminación de la técnica colorista esbozada en $\mathrm{El} \mathrm{siglo} \mathrm{de} \mathrm{las} \mathrm{luces.} \mathrm{En} \mathrm{esta} \mathrm{novela} \mathrm{la}$ escena madrileña del levantamiento del 2 de mayo de 1808 se tiñe de una vasta gama de rojos, símbolo de la revolución, las pasiones desencadenadas por el conflicto y el derramamiento de sangre que concluyen la obra. En el primer capítulo de Concierto barroco, envuelto en una atmósfera de barroquismo colonial muy a lo Sor Juana Inés de la Cruz. Carpentier sigue un proceso análogo al abrir y cerrar la escena inicial con las palabras "de plata", metal y marco simbólico de la mayor fuente de riqueza del México virreinal. Un rico minero criollo, nieto de españoles, ha llegado al bienestar y decide recorrer Europa para divertirse en compañia de su criado indio. El paralelismo que existe entre amo y cirado "Francisquillo...remedando al Amo, y meando al compás del meado del amo, aunque no en bacinilla de plata sino en tibor de barro...coreando, como en oficio de iglesia: 'Aquí lo que se queda...Acá lo que se va' ", recuerda a la vez las estrechas relaciones entre el

\footnotetext{
1 “Nueva entrevista con Alejo Carpentier"' de próxima aparición en Insula, Madrid.
} 
Cimarrón y Perro en "Los fugitivos", , o Melchor y Canelo en "Viaje a la semilla", 2 Y el recargado ambiente lujoso en que abre el relato también tiene antecedentes en determinadas escenas de la catedral de Santiago de Cuba en "Oficio de Tinieblas".

Tanto los objetos ornados como su mismo color plateado exteriorizan la suntuosidad y la intención decorativa, pictórica, del primer capítulo. $\mathrm{Y}$ los detalles escultóricos de plata cincelada, los materiales preciosos - seda, telas, joyas- y los objetos exóticos -chinerías, japonerías- evocan el atractivo sensual parnasiano frente a los materiales y sensaciones táctiles. Pero mientras que la prosa musical, esmeradamente trabajada, llena de rima interna y aliteraciones, se aproxima a los ideales gratos a la estética modernista, el tono zumbón y los pormenores carnales de una rebuscada vulgaridad, lo alejan de canones anteriores a la vanguardia. A la vez el sentido plástico de la prosa tiene un doblaje paródico en la sonoridad de su propio estilo pulido, consciente del impacto y valor de sus repeticiones: "Y todo esto se iba llevando quedamente, acompasadamente, cuidando de que la plata no topara con la plata, hacia las sordas penumbras de cajas de madera..." (9). Este doblaje se mantiene a través del relato que poco a poco, mediante el uso de las enumeraciones, el ritmo lento, la sintaxis compleja y un tono irónico, va cobrando el aspecto de un croquis típicamente "barroco" " o, tal como lo describe el autor " ...enredado en sí mismo, cerrado en volutas, desenrollado luego para enrollarse otra vez..." (11).

En el segundo capítulo amo y criado llegan a La Habana, ciudad castigada por la fiebre amarilla, que también trae a la memoria el Santiago de Cuba decimonónico azotado por la epidemia en "Oficio de Tinieblas"'. De ahí que la escena adquiera un tenue matiz amarillento por medio de tres ligeros toques de color--oro, amarillo y azufre--que carecen de la intensidad de los brillantes y sostenidos tonos plateados del cuadro mexicano. Como los habaneros están sometidos a los trabajos de la muerte, sepultando a los difuntos en un camposanto atiborrado de cadáveres, los viajeros se refugian en la vecina villa de Regla. Cuando el indio Francisquillo sucumbe a la fiebre, el mexicano toma en su servicio a un criado negro, Filomeno, músico de tambor y guitarra, nieto de un cierto esclavo Salvador. Se trata del personaje que recibe el más exaltado elogio en el Espejo de paciencia donde se cuenta la prisión que el Capitán Gilberto Girón bizo a la persona del Ilustrísimo Señor $D^{n}$ Fray Juan de las Cabezas Altamirano, Obispo de la Isla de Cuba, en el puerto de Manzanillo. El poema épico en octavas reales escrito en 1608 por Silvestre de Balboa y Quesada, "natural de la isla de Gran Canaria; vecino de la villa del Puerto Príncipe", hoy la ciudad de Camagiiey, es la primera manifestación literaria conocida de Cuba. En el poema Balboa celebra la derrota de los piratas franceses que robaron al obispo Altamirano para rescate, a manos de los habitantes de Báyamo, en 1604. Veintiséis hombres bajo el mando del hidalgo Gregorio Ramos, formaron una tropa que se emboscó en la playa de Manzanillo "a diez leguas y una más" de la ciudad y venció a los corsarios en reñida lucha. Y en el breve episodio de Espejo de paciencia que reproducimos a continuación, se cuenta cómo el negro Salvador se distinguió entre los defensores más destacados que pelearon en este lugar contra los bucaneros del siglo XVII:

2 Cito por la edición española de Concierto barroco, Madrid: Siglo XXI de España Editores S.A., diciembre de 1974, pág. 10. Todas las citas posteriores se refieren a esta edición. De aquí en adelante me limitaré a poner el número de la página entre paréntesis. 
Andaba entre los nuestros diligente Un etiope digno de alabanza, Llamado Salvador, negro valiente, De los que tiene Yara en su labranza;

Hijo de Golomón, viejo prudente:

El cual armado de machete y lanza, Cuando vido a Gilberto andar brioso Arremete contra él cual león furioso.

Don Gilberto, que vido el etiope,

Se puso luego a punto de batalla:

y se encontraron; más quedó del golpe Desnudo el negro y el francés con malla. Oh, tú, divina musa Caliope, Permite, y tu bella ninfa Aglaya, Que pueda dibujar la pluma mía De este negro el valor y valentía.

Andaba Don Gilberto ya cansado, $Y$ ofendido de un negro con vergüenza:

Que las más veces vemos que un pecado Al hombre trae a lo que nunca piensa: $\mathrm{Y}$ viéndole el buen negro desmayado, Sin que perdiese punto en su defensa, Hizose afuera y le apuntó derecho Metiéndole la lanza por el pecho.

Mas no la hubo sacado cuando al punto El alma se salió por esta herida, Dejando el cuerpo pálido y difunto, Pagando las maldades que hizo en vida. Luego uno de los nuestros que allí junto Estaba con la mano prevenida,

Le corta la cabeza, y con tal gloria

A voces aclamaron la victoria.

¡Oh, Salvador criollo, negro honrado! Vuele tu fama, y nunca se consuma: Que en alabanza de tan buen soldado Es bien que no se cansen lengua y pluma. $\mathrm{Y}$ no porque le doy este dictado, Ningún mordaz entienda ni presuma Que es afición que tengo en lo que escribo A un negro esclavo, y sin razón cautivo 


\author{
$\mathrm{Y}$ tú, claro Bayamo peregrino \\ Ostenta ese blasón que te engrandece; \\ $\mathrm{Y}$ a este etiope. de memoria dino, \\ Dale la libertad pues la merece. \\ De las arenas de tu río divino \\ El pálido metal que te enriquece \\ Saca, y ahorra antes que el vulgo hable, \\ A Salvador el negro memorable. ${ }^{3}$
}

Por lo demás, en el resto del segundo capítulo de Concierto barroco hay un escaso repertorio cromático donde el blanco y azul son colores emblemáticos relacionados con las tierras mexicanas por el fulgor de la plata y la intensidad azul de su cielo despejado característico de lo que Humboldt llamara "la región más transparente del aire". Y la casaca "roja" y la peluca 'blanca", de colores de valor antitéticos al negro, sirven para destacar la raza y el color del nuevo criado con quien el rico criollo ha de llegar a España en el capítulo siguiente.

Comparado con el suntuoso ambiente mexicano que abre el relato, notamos en el nuevo ambiente europeo del tercer capítulo una ausencia casi total de colorido. Madrid es una ciudad apagada, sucia, pobre y triste, en plena decadencia. La comida es sosa y monótona, las mujeres escuálidas y en los sórdidos prostíbulos tocan orquestas de ciegos mutilados, personajes dignos de la prosa más negra de Quevedo: “...un ama obesa, ñata, bizca, leporina, picada de viruelas, con el cuello envuelto en bocios, cuyo ancho trasero movido a palmo y medio del suelo era el de algo así como una enana gigante"'(28). Por ello, aparte de "carne blanca", referencia a las prostitutas, los únicos tonos de color se vinculan a asociaciones americanas: portadas de "azulejos", aquí una alusión a un friso mexicano cubierto de cerámica, el sirviente negro, las salsas oscuras con aroma de chc:olate, cangrejos de carnes leonadas, los trajes recamados de plata del protagonista mexicano. Unicamente cuando al final del capítulo amo y criado dejan el Madrid sombrío y recorren las tierras del Quijote, asoma un rayo de claridad: " "posadas blancas cada vez más blancas" (30). Los personajes de la novela, camino a Barcelona, aquí pasan por áreas geográficas que ya vio Carpentier al asistir el II Congreso Internacional de Escritores Antifascistas. Además el escritor describió su viaje por Tarancón, Minglanilla, Cuenca, Valencia y el Levante, en el artículo "España bajo las bombas" publicado en la revista habanera Carteles el 12 y 26 de septiembre y el 10 y 31 de octubre de 1937 . Y la festiva llegada de los viajeros a Barcelona se basa en el capítulo LXI de la segunda parte de $E l$ Quijote: "De lo que sucedió a Don Quijote en la entrada de Barcelona con otras que tienen más de lo verdadero que de lo discreto"'.

El capítulo cuarto de Concierto barroco abre con una vasta gama cromática de tonos ácueos que pasan del gris, aneblado, sepia, ocre, ópalo, a matices crepusculares y el azul pastel. Es como si la paleta utilizada por el autor ya estuviera prefigurada en el cuadro Tres bellas venecianas de Rose-Alba Carriera (1675-1757), pintora famosa en su época por sus

3 Silvestre de Balboa, Espejo de paciencia ed. y notas de Cintio Vitier, Santa Clara: Universidad Central de las Villas, 1960 , págs. 82-84. 
exquisitos lienzos y miniaturas al pastel, mencionado en el primer capítulo: “...en un pequeño salón...aparecían tres figuras debidas al pincel de Rosalba pittora, artista veneciana muy famosa, cuyas obras pregonaban, con colores difuminados, en grises, rosas, azules pálidos, verdes de agua marina, la belleza de mujeres tanto más bellas por cuanto eran distantes" (11-12). Y así por la estrecha correspondencia de valor emotivo y cromático de colores predominantemente pálidos, la prosa pinta una acuarela veneciana simbólica del ambiente marino de esta ciudad lacustre. No obstante, se trata de una anti-Venecia, libre de todos los tópicos y asociaciones gratuitas de este tan manoseado ambiente italiano. $\mathrm{Y}$ por ello procuramos en vano personajes de la "Commedia dell'arte", arlequines en busca de colombinas navegando en góndolas bajo el Puente de los Suspiros. Pero de pronto el silencio y los diluidos tonos iniciales estallan en un "mareo de colores" chillones y sonidos estridentes de una escena bañada por las luces de barcos y fuegos artificiales del carnaval veneciano. Aparte de su trasfondo llamativo--amarillo naranja, verde rana, amarillo mandarina, amarillo canario, rojo granate, añil y azafrán--los tonos vivos apuntan hacia una preocupación visual y gráfica, de lejana ascendencia cubista, que también se refleja en los diseños ajedrezados y listados de los disfraces y máscaras, tanto como en los dibujos, colores y movimiento implícitos en la iluminación de distintos tipos de cohetería. Las bengalas, girándulas y meteoros transforman el cielo veneciano en una caja de luz. Todas estas expresiones del regocijo y del carpe diem, contrastan con el estado de ánimo anterior en el cuadro sombrío de las escenas matritenses.

En la Botteghe di Caffé el amo mexicano y Filomeno, el uno disfrazado de Montezuma, el otro sencillamente de negro, por el exotismo de su raza en medio de máscaras blancas, se encuentran con un fraile pelirrojo, y un forastero napolitano acompanado de un extranjero sajón llamado Jorge Federico. Después de una animada discusión sobre el éxito de la ópera Agripina que acaba de estrenar en el teatro Grimani y beber un rato, el grupo decide retirarse a un convento para hacer música. Con el objeto de rematar el aire carnavalesco de este gran escenario dedicado a la representación colectiva y entregado al goce desenfrenado de los sentidos, la descripción del ambiente veneciano termina con una profusión de colores fuertes de máscaras blancas, verdes, negras, amarillas y una torrente de sonidos ofensivos: las palabrotas de una pescadora enfurecida.

El claroscuro de la escena inicial del quinto capítulo recuerda un cuadro de escuela flamenca, "Leidener Frihzzeit" (1626-31) de Rembrandt; la tenue iluminación de velas, candelabros y faroles proyecta débiles rayos que se reflejan y corren sobre las labradas superficies retorcidas de una enorme sala de música. Es el interior del Ospedale della Pietá " "...algo como un teatro sin escenario o una iglesia de pocos altares..." (42), donde se ha de celebrar un prodigioso "concerto grosso" en una inesperada culminación del carnaval veneciano. A lo largo del capítulo aparecen fugaces toques de color-.."cortinas y dorados", "figuras claras'.' es decir, los hábitos de las huérfanas, "Eva flacuchenta y amarilla", la "Serpiente...listada de verde" en un cuadro del paraíso, probablemente Il peccato originale

\footnotetext{
4 Para una discusión más detallada de las relaciones de Carpentier y los -ismos de vanguardia véase mi articulo "Corrientes vanguardistas y surrealismo en la obra de Alejo Carpentier" y "Lo real y lo maravilloso en El reino de este mundo" ' de Emir Rodríguez Monegal, ambos artículos en A sedios a Carpentier: once ensayos criticos sobre el novelista cubano, Santiago de Chile: Editorial Universitaria y New Haven, Conn.: Yale University Antilles Research Program, Dept. of Latin American Studies, 1972.
} 
de Jacopo Robusti Tintoretto (1518-1594), “alfombra encarnada"--colores de sentido simbólico tradicional: riqueza o lujo, la pureza, la desesperación, el mal, animación o emoción ardiente. Pero en general hay una ausencia casi absoluta de colores en este ambiente poco iluminado por el juego de luz y sombra porque en el claroscuro de esta escena clave de Concierto barroco, la atención se concentra en toda clase de sonidos y matices auditivos. Este fenómeno llega a tal punto que algunos personajes se deshumanizan y se van despojando paulatinamente de su identidad hasta convertirse en puros tonos musicales: "Como si las muchachas no tuviesen otra personalidad, cobrando vida en sonido..." (42).

El fraile pelirrojo, el napolitano y el sajón que se habian reunido en la fonda del capítulo anterior, el cuarto capitulo, ahora se revelan como los compositores Antonio Vivaldi (1678-1741), Domenico Scarlatti (1685-1757) y Jorge Federico Haendel (16851759). Estos protagonistas datan precisamente la época en que transcurre la mayor parte del relato, ya que los dos músicos italianos y el alemán efectivamente coincidieron en Venecia el 26 de diciembre de 1709. En medio del Hospital de la Piedad los compositores, acompañados por una orquesta formada de huérfanas, inician un funambulesco "concerto grosso" en el que por fin también irrumpe el criado Filomeno cantando y participando en la sesión musical con una improvisada batería de sartenes, calderos y otros utensilios sacados de la cocina. Como ya lo había explicado Carpentier en el capítulo XVI "Afrocubanismo", de La música en Cuba (1946), lo que canta el negro es la canción criolla "Mamita, mamita/yen, yen, yen/ Que me come la culebra,/ yen, yen, yen,/ un canto para "matar la culebra" y asunto de comparsa en las celebraciones del carnaval habanero. " Sobre esta supervivencia totémica del culto dahomeyano de la culebra, Nicolás Guillén también ha elaborado su famoso poema "Sensemayá'.

Cuando Filomeno termina su canción con el estribillo de Ca-la-ba-són/ Son-són, / Cala-ba-són/ Son-són,/ los europeos, acostumbrados al latín litúrgico, lo interpretan como Kábala-sum-sum-sum, "un sonsonete cien veces repetido" en coro por los personajes que acaban formando una fila de conga que culebrea por los pasillos del hospital. Pero con el toque de maitines las huérfanas se desdibujan en una progresiva desrealización hasta convertirse en blancas figuras que se esfuman como "ánimas de teatro" en el interior del convento. La monja llena una canasta con meriendas y los huéspedes se embarcan con un misterioso Barquero.

Al principio del capítulo sexto los compañeros de parranda deciden desayunar sobre las lápidas de un cementerio donde cada uno narra la historia de su vida. Al fraile pelirrojo le interesa la de Montezuma como asunto para una ópera que piensa estrenar en el teatro San Angelo, y el negro Filomeno vuëlve a narrar las hazañas de su abuelo Salvador Golomón. $\mathrm{Y}$ es aquí dondo Carpentier introduce por primera vez un elemento claramente anacrónico en el relato, cuando los presuntos protagonistas barrocos descubren una lápida inscrita con el nombre de Igor Stravinsky, el compositor ruso y amigo del novelista cubano, que falleció en Nueva York el 6 de abril de 1971 y se halla enterrado cerca de Venecia. Se trata pues, del antiguo camposanto de los capuchinos en San Michele, y el improvisado desayuno de Vivaldi, Scarlatti, Haendel, amo y criado, transcurre en nada menos que la década de los setenta de nuestro siglo.

5 Cito por la edición cubana, La Habana: Editorial Luz Hilo, 1961, pág. 164. 
Mientras que el trastorno del aparente riguroso orden cronológico dentro del marco barroco que ha reinado hasta el momento, es inesperado y desconcertante, una segunda y más atenta lectura revela cómo de costumbre Carpentier ha preparado meticulosamente el terreno para el cambio temporal. Repasando rápidamente la cronología de los primeros cinco capítulos, notamos que en el primero apenas hay referencias temporales vagas e imprecisas donde el autor se limita a indicar que las escenas transcurren de noche. Pero los nombres de Coyoacán, Montezuma, Hernán Cortés, Tenochtitlán etc.; tanto como el ambiente lujoso y la acumulación de voces mexicanas, nos hacen pensar en un indeterminado momento del barroco mexicano. Pero el ámbito temporal ya empieza a concretarse en el segundo capitulo al decir que Filomeno es biznieto del “ "...negro Salvador que fue un siglo atrás, protagonista...en una larga y bien rimada oda, titulada Espejo de Paciencia" (20). Como se sabe que Balboa terminó de escribir su obra el 30 de julio de 1608, esto ubica la acción del cuento en la Villa de. Regla, cerce de La Habana, precisamente “...en aquel amanecer de septiembre..." (26) de 1709. Este año también explica las alusiones al Hamlet de Shakespeare en el segundo, cuarto y sexto capítulo, sobre todo en relación al Rey de Dinamarca, presunto Conde de Olenborg del cuarto capítulo. Si investigamos un poco la vida de la pintora Rosalba veremos que el rey Federico IV de Dinamarca efectivamente estuvo en Venecia en el año 1709 , se dejó retratar por ella y le encargó doce miniaturas de las venecianas nobles más hermosas. ${ }^{6}$ Pero es hora de que volvamos a la cronología. Considerando que las travesías de aquella época duraban unos dos meses, se puede concluir que las escenas madrileñas del tercer capítulo se desarrollan a fines de otoño del mismo año. Los viajeros interrumpen la estancia en la corte "...para llegar cuanto antes a Italia, donde las fiestas de carnaval...empezaban en Navidad”" (29). Por ello el cuarto capítulo transcurre durante el carnaval de Epifanía (35), momento fácilmente comprobable por el estreno de la Agripina. La ópera de Haendel se representó por motivo del inicio de la temporada de invierno, el 26 de diciembre de 1709, con el papel principal a cargo de Margherita Durastant en el Teatro Giovanni Crisostomo de Venecia, propiedad de la familia Grimani. ${ }^{7}$ Además, todo apunta hacia esta fecha clave del relato, puesto que el 26 de diciembre, cumpleaños del autor cubano y día de San Esteban, también es la fiesta patronal del héroe del mismo nombre, en El siglo de las luces. Es fácil advertir que el quinto capítulo encaja dentro del marco temporal anterior y transcurre durante la misma noche. Pero en este esquema temporal dieciochesco, intermitente y lineal, ya asoman varios sutiles e intencionados anacronismos anunciando las sorprendentes rupturas cronológicas del desenlace. Para entender absolutamente este mecanismo anticipador, volvamos al texto y veamos cual es su significado.

En el segundo capitulo el novelista describe a Salvador, el tartarabuelo de Filomeno, como "...negro valiente/ de los que Yara tiene en su labranza" (23). Pero la verdad es que este verso de Balboa debe parte de su fortuna literaria en nuestro tiempo, a la resonancia y el enriquecimiento del campo semántico que el nombre de Yara ha adquirido en Cuba con ciertos acontecimientos políticos del siglo XIX. Por lo tanto es muy probable que cualquier

6 Ulrich Thieme \& Felix Becker, Allgemeines Lexikon der Bildenden Kunst, vol VI, Leipzig: Seeman, 1912, pág. 75.

7 Die Musik in Geschichte und Gegenwart: Allgemeine Enzyklopidie der Musik, herausgegeben von Friedrich Blume, Band 5, Kassel \& Basel: Bärenreiter Verlag 1956, pág. 1239. 
lector cubano inmediatamente asocie el nombre con el concepto de soberanía nacional y ¡Viva Cuba libre!, el "grito de Yara". Así se suele llamar la primera declaración de la independencia cubana el 10 de octubre de 1868, proclamada en el barrio de Yara, ciudad de Manzanillo, provincia de Oriente por el patriota Carlos Manuel de Céspedes (1819-1874), también oriundo de Báyamo. Otra irónica referencia al futuro, menos oblicua y más universal, ocurre al final del tercer capitulo cuando los viajeros llegan a Barcelona. El amo se dirige a su criado y habla de las multitudes que circulan por los muelles, a manera de insectos: "Parecen hormigas... Si los dejas, levantarán edificios tan altos que rascarán las nubes' (31). Aqui por boca del mexicano ya hay una alusión indirecta a la arquitectura característica del siglo veinte, en que se desarrollarán ciertas escenas en determinados momentos del sexto y del octavo capítulo.

Y en el capítulo quinto que transcurre en el Hospital de la Piedad, Haendel hace un comentario sobre el baile de figuras de las huérfanas que no tenian nombre propio, porque se las llamaba por el nombre del instrumento que tocaban--Pierina del violino, Cattarina del cornetto, Bettina della viola etc.--y exclama: "Todos los instrumentos revueltos... Esto es algo así como una sinfonía fantástica" (47). Cuando un escritor y musicólogo de la talla de Carpentier, que en el año 1954 escribió un artículo sobre el $150^{\circ}$ aniversario del nacimiento de Héctor Berlioz por el que, dicho de paso, tampoco siente mayor admiración, pone estas palabras equívocas en boca de un compositor alemán, nos hace sospechar que se trate de una irónica referencia a la Sinfonie phantastique: episode d'une vie d'artiste (1830). ${ }^{8} \quad$ Esta obra musical que el compositor romántico francés basó en las Confesiones de un opiómano inglés de Thomas de Quincey, consiste de cinco partes: "Ensueños y pasiones", 'Un baile", "Escena campestre"', "Marcha al suplicio'” y "Sueño de una noche de aquelarre". Y es justamente en este último tiempo donde aparece una elaboración sonora inspirada en la melodía gregoriana del siglo trece, el "Dies Irae". Es la célebre secuencia musical sobre el poema en latín cuya visión del Juicio Final acompaña tradiçionalmente en la liturgia de la Iglesia Católica a las misas de requiem y los oficios de los muertos. La analogía con el cuento, cuyo quinto capítulo también es una especie de noche sabática, es clara, ya que aquí, como en la sinfonia de Berlió, se preludian las notas que anuncian la próxima escena que tiene lugar en el cementerio de San Michele, entre personajes que se han de revelar como fantasmas. Las últimas líneas del capítulo nos permiten verificar esta interpretación, puesto que los huéspedes del hospital embarcan con un Barquero. El uso de la mayúscula hace incluso evidente que aquí se trata de Caronte, el barquero de los infiernos por antonomasia, que traslada las almas de los difuntos a la otra orilla de la laguna Estigia.

Los distintos anacronismos que acabamos de examinar ilustran que el acostumbrado juego temporal de barajar el presente, pasado y porvenir ha sido cuidadosamente observado hasta romper y rebasar deliberadamente el marco barroco dieciochesco con que el autor encuadra los acontecimientos ficticios e históricos de los primeros cinco capítulos de Concierto barroco. Y antes de eliminar los nexos temporales establecidos, Carpentier consigue una transición muy fina y lograda que súbitamente coloca al lector en el sexto capítulo en plena reunión de sombras que se van desdibujando en el brillante amanecer de un día cuyas horas se aceleran y en seguida llevan al crepúsculo.

\footnotetext{
8 'Hector Berlioz", El Nacional, Caracas, miércoles 27 de enero de 1954, pág. 28.
} 
Si consideramos brevemente los colores predominantes o las referencias a fenómenos lumínicos, observaremos que el código cromático del sexto capítulo subraya este ambiente espectral: "sombras, grisáceas, luces...apagarse, claridad, perdiendo...brillo, negro...blanca, negro...blanca, blanqueando, peplos apolillados y púrpuras, negro, negro, blancos resplandores, verde profundo, mucha luz, motetes en petirrojo mayor, sombras, negro, negras, fríos reflejos de bronce, bronce'". El único caso de empleo realista de colorido es "peplos apolillados y púrpuras"' (51) referencia a disfraces de teatro utilizados en la temporada pasada. A esta misma concepción realista obedece el término "pelirrojo", para Vivaldi, a quien sus contemporáneos efectivamente llamaban "il prette rosso" por su cabellera rojiza, y "negro" para Filomeno. Con la excepción de madrigales y "motetes en petirrojo mayor" (55) juego de palabras sinestético en referencia a pájaros, los colores restantes se pueden resumir como matices de blanco y negro, dos colores primarios que están en oposición cromática. El blanco, color neutro, acromático, de mayor resplandor e intensidad lumínica, es empleado de manera simbólica para reflejar en el ambiente, la condición espiritual de almas, o subrayar la deshumanización total de protagonistas fantasmales. El negro, el color más obscuro, o el resultado de la ausencia total de luz, aquí mantiene su sentido simbólico tradicional de luto. Lo mismo ocurre con el verde profundo o bronce que aquí representan lo triste o irremediablemente trágico. El uno por ser color de cipreses, árboles de cementerio, el otro por ser metal de ataúdes y martillo de reloj cuyo oficio es medir las horas que nos aproximan paulatinamente a la muerte.

Los momentos del resto del capítulo sexto transcurren en un crepúsculo que completa el trastorno temporal. De pronto, cuando los juerguistas navegan frente al palacio Vendramin-Calergi, Montezuma y Filomeno ven el cortejo fúnebre de "...un músico alemán que murió ayer de apoplejía... A hora se llevan los restos a su patria” (56). Es el cadáver de un gran compositor de óperas, ahora conducido a una góndola negra--la primera concesión manifiesta al ambiente veneciano en que transcurre el cuento--y la lancha transporta el ataúd a una estación de ferrocarril donde espera una máquina que ha de trasladarlo a Alemania: "...resoplando entre brumas, esperaba la locomotora de Turner con su ojo de cíclope ya encendido' (56). Para un lector aficionado a la música, la identificación del muerto como Ricardo Wagner (1813-1883) quien efectivamente murió en Venecia, y la referencia a la fecha de esta escena, el 14 de febrero de 1883 , no puede ser más explícita. Como se sabe, Wagner fue a invernar en Venecia el 14 de septiembre de 1882, se: hospedó en el Palazzo Vendramin, murió en esta ciudad el 13 de febrero de 1883 y fue enterrado en el jardín de la Villa Wahnfried de Bayreuth el 18 de febrero del mismo año.9 $\quad$ Y un admirador del arte inglés no tardará en descubrir la alusión al famoso cuadro Rain, Steam and Speed: the Great Western Railwav (1844) del pintor Toseph Mallord Turner (17751851). La locomotora es una de las primeras reproducciones de un tren en la pintura del siglo diecinueve, aunque el verdadero tema del cuadro quizás sea los efectos lumínicos producidos por el rápido foco de luz visto a través de la lluvia. Ahora ya es demasiado evidente que además de los indicios que colocan'el capítulo indiscutiblemente en el siglo veinte, Vivaldi Haendel, Scarlatti, amo y criado, son protagonistas que actúan en un

\footnotetext{
${ }^{9}$ Die Musik in Geschichte und Gegenwart: Allgemeine Enyklopädie der Musik, Band 14, Kassel: Burenreiter Verlag 1968, pág: 103
} 
tiempo cósmico. En esta eternidad no sujeta a las leyes de la cronología normal, donde los años son como horas, los personajes pueden viajar en cualquier dirección, del siglo dieciocho, al veinte, al diecinueve. Por ello, de los años 1709 , 1791 y 1883 , tres hitos fundamentales en la narración del capítulo sexto, hay otro salto hacia el siglo dieciocho, en el capitulo séptimo.

Cuando el mexicano que se había acostado en la posada después de trasnochar durante el carnaval se despierta de un sueño profundo, encuentra que el año en curso es el otoño de 1733, el día del ensayo general de la ópera Motezuma. Alvise Giusti, el autor del libretto, lo redactó sobre una traducción de la Historia de la conquista de México, población y progresos de la América Septentrional, conocida por el nombre de Nueva España de Antonio de Solis y Rivadeneira (1609-1686). Como esta crónica española se tradujo al italiano en 1699, y una segunda traducción se publicó en Venecia en 1704, el libretto de Giusti para la música de Vivaldi estrenada en 1733, es la primera aparición de un tema americano en la ópera universal. Además es fácil de comprobar que el esquema cromático de este capitulo refleja la influencia de la representación escénica: "grisura, neblinosa, voces de bronce, telón encarnado, negro, tornasol de flámulas, oriflamas y banderolas de púrpura y amaranto, esplendores, oriflamas aztecas, terciopelo encarnado, telón encarnado, luminosa visión, sacerdote...blanco, pelirrojo, estuche fucsina, vellocino rojo, neblinosas garúas, esmaltes y oros'. La breve alusión al ambiente veneciano otoñal que abre y cierra el capitulo, está resuelto en tonos grises y aneblados que por fin encubren los esmaltes y oros de la torre del tiempo, el Orologio con martillos de bronce. Esta paleta oscura de un día lluvioso que empasta todo lo que rodea--bronce, esmaltes, oro--despide escasa luminosidad pero se relaciona con los tonos ácueos de la marina que abre el capitulo cuarto. El traje "negro" y la cabellera "rojiza" de Vivaldi y posiblemente los sacerdotes vestidos de "blanco", son los únicos colores de valor real. Por lo demás se demuestra el estruendo de color en el palco, mediante briosos golpes de rojo cuyo dinamismo se subraya por hallarse sobre un fondo escénico de banderolas y gallardetes. Tornasol de flámulas, oriflamas de purpura y amaranto, oriflamas aztecas, telón encarnado, terciopelo encarnado, estuches color fucsina y vellocino rojo, todos hacen resaltar el valor simbólico de animación y emoción ardiente producidos por un espectáculo que cobra aun mayor nitidez con el resplandor de las candilejas. Esta gama de encarnados es casi la última manifestación colorista de un Concierto barroco que termina con dos ligeras manchas de color.

La acción del capítulo octavo en un principio parece ser una continuación en la tarde del otoño de 1733, pero en seguida revela que realmente transcurre el siglo veinte. El azulado de una iluminación municipal evocando gas o neon nos pone sobre la pista, y la petaca con adorno de calendario azteca, el ferrocarril, los Wagons Lits son huellas que van confirmando esta impresión. Por fin una serie de detalles concretos hace muy evidente que amo y criado--protagonistas arquetípicos que actúan sobre el mismo escenario a través del tiempo--ahora se encuentran en el año 1969 o a principios de la década de los setenta. La cuidad de Venecia está notablemente envejecida y hundiéndose en el fango, la lancha del barquero ahora tiene un motor, y se alude al aterrizaje del hombre en la luna, que, como es sabido, ocurrió con la misión Ápolo II, el 20 de julio y 19 de noviembre de 1969 . La novela concluye cuando el negro se despide de su amo para asistir a un concierto de jazz de Louis Armstrong donde empezará a sonar otro "concierto barroco" asombrosamente 
moderno. $\mathrm{Y}$ es en la breve descripción del teatro donde tiene lugar el nuevo concierto donde Carpentier nos da el último toque de color que posiblemente encierre clave y sentido de su afán colorista: la inmovilidad y permanencia de las altas creaciones artísticas a través de las edades. "Y embocando la trompeta, atacó como él sólo sabía hacerlo, la melodía de Go Down Moses...Alzada por el pabellón de cobre hacia los cielos del teatro donde volaban, inmovilizados en un tránsito de su vuelo, los rosados ministriles de una angélica canturia, debida acaso, a los claros pinceles de Tiépolo' (82). La alusión a Giambattista Tiépolo (1696-1770) sirve de apropiado colofón para la novela porque al último gran maestro del arte veneciano también le fascinaba el Nuevo Mundo; así lo demuestra el fabuloso fresco Alegoría de América (1750-53) en la sala imperial del palacio de Würzburg donde aparece una exótica india emplumada, exuberante buena moza, sentada en un gigantesco caimán.

Por lo demás el lector asiduo del escritor cubano que ha seguido esta exposición, habrá notado que en la novela asoman los temas carpenterianos predilectos que se repiten por medio de constantes variaciones y diferencias en distintas obras a través de los años: el arte--aquí sobre todo la música, pero también la pintura--como tarea vital que ofrece la mejor manera de remontar y dominar el tiempo; la decadencia de la cultura occidental; la exaltación de los valores americanos; la inmutabilidad de la naturaleza humana a lo largo de la historia. Filomeno concibe la mayor realización que cabe al hombre en el reino de este mundo como el dominio del arte temporal por excelencia: "Y parecíale...que, al fin y al cabo, lo único vivo, actual proyectado, asaetado hacia el futuro, que para él quedaba en esta ciudad lacustre, era el ritmo, los ritmos, a la vez elementales y pitagóricos, presentes acá abajo, inexistentes en otros lugares..." (81), " "..por lo pronto, se las entendía con la música terrenal--que eso, de música de esferas, lo tenía sin cuidado"' (82). La decadencia de la cultura europea asoma en la visión desengañada de un Madrid dieciochesco basado en los episodios más negros de la novela picaresca, tanto como en la pintura de una Venecia de nuestro tiempo como organismo enfermo, irremediablemente corroido y mutilado por la devastación de los siglos:

...la ciudad había envejecido enormemente. Salíanle arrugas en las caras de sus paredes cansadas, fisuradas, resquebrajadas, manchadas por las herpes y los hongos anteriores al hombre que empezaron a roer las cosas no bien éstas fueron creadas...; ...la agresividad de olas mínimas, pero empeñosas y constantes, que se rompian sobre pilotajes, patas de palo y muletas, que todavía alzaban sus mansiones, efímeramente alegradas, aquí, allá, por maquillajes de albañilería y operaciones plásticas de arquitectos modernos... (80)

En contraste explícito y estrechamente unido a este tema va la apoteosis de lo criollo, todos los valores netamente americanos en sus diversas manifestaciones locales, sean mexicanas, cubanas o, como en otras obras, de fondo venezolano:

...evocaba el mexicano la sutileza de los peces guachinangos y las pompas del guajolote vestido de salsas obscuras con aroma de chocolate y calores de mil pimientas...; cantaba el negro los méritos del aguacate pescuezudo y tierno, de los 
bulbos de malanga que, rociados de vinagre, perejil y ajo, venían a las mesas de su país, escoltados por cangrejos cuyas bocas leonadas tenían más sustancia que los solomos de estas tierras (28)

Y en la página siguiente el amo concluye que todo el ambiente madrileño "...poca cosa era, en verdad, comparado, con lo quedado en la otra orilla del Océano..." (29). La inmutabilidad de la naturaleza humana a través del tiempo se manifiesta en la presencia de los arquetipos amo y criado a lo largo del relato, y en las afinidades de dos negros de distintas edades y culturas, dedicados a la música popular o al jazz: Filomeno, lejano precursor antillano y equivalente de Louis Armstrong. Además esta preocupación central de Carpentier por la música se refleja en el título de Concierto barroco y en la presencia de seis protagonistas músicos a lo largo de la novela.

Como todas las obras del escritor cubano son de una estructura trabajada y precisa, rigurosamente documentable, conviene cerrar esta disquisición con un breve cotejo de las principales fuentes históricas sobre las que descansa el relato: el Espejo de paciencia; Les Confessions (1781 y 1788) de Jean-Jacques Rousseau (1712-1778); las Lettres Familiéres sur L'Italie (1739) o Lettres Italiennes como también suelen llamarse las cartas del Presidente Charles de Brosses (1709-1777); Some Observations made in Travelling through France, Italy \& $\mathrm{c}$ in the Years MDCCXX, MDCCXXI and MDCCXXII (1730) de Edward Wright; Motezuma, drama per muisica (1733), el libretto de Alvise Giusti pasa la partitura de Vivaldi. A Silvestre de Balboa, ya examinado anteriormente, se alude en el propio texto de la novela, cuyo segundo capítulo sigue fielmente pero a grandes trazos, la historia narrada por el poeta canario. Carpentier intensifica el dramatismo de su relato al convertir a un personaje secundario, Salvador Golomón, en el protagonista principal, y concentrar la mirada en la figura del bisnieto negro quien describe con imágenes provenientes de su propia realidad, cómo el abuelo mató al capitán de piratas. Pero en general hay pocos cambios de los incidentes de el Espejo de paciencia y todos obedecen a la lógica interna de dramatizar la narración. Así uno de ellos ocurre cuando los sátiros, faunos, silvanos, semicarpos, centauros, hamadriadas silvestres de la mitología griega, saludan al buen obispo cuando regresa a sus tierras de Yara, al fin del primer canto del poema épico. En la novela los seres fantásticos acuden a un enorme fin de fiesta en Báyamo donde se celebra la muerte de Gilberto, cuya cabeza ha sido puesta como trofeo en la punta de una lanza en la plaza pública. Y todos ellos sirven a Carpentier para subrayar la vigencia de lo maravilloso en el continente americano. A la vez las sutiles variaciones de enfoque o tono sobre los sucesos narrados en los versos de Balboa, destacan lo singular o insólito de estos acontecimientos, mejoran la tensión dramática en el relato y hacen que la escritura se enriquezca de nuevas conotaciones aparte del texto del poema que le dio origen. Algo semejante ocurre con los libros de Rousseau, de Brosses, 'W right 'y el libretto de Giusti. Tanto Les Confessions corno las Lettres Familieres sur L'Italie y Some Observations made in Travelling through France, Italy $\& c$, sobre las que se basa parte del fondo veneciano del cuarto, quinto, sexto, séptimo y octavo capítulo de Concierto barroco, son libros de viaje de la primera mitad del siglo XVIII, y con la excepción del libro de Wright, ligeramente posteriores a la época en que transcurre la novela. Si a continuación reproducimos las partes principales a fin de facilitar el análisis, es para que el estudioso aprecie como la 
recreación carpentieriana se distingue de todos los textos anteriores por su ironía, enfoque, estilo y punto de vista. Un lector ni curioso ni impertinente las saltará sin pena ni gloria y sin perder el hilo de esta exposición. Veamos primero el texto del historiador y geógrafo Charles de Brosses quien también llegó a ser presidente del parlamento de su ciudad natal de Dijon y desde 1774, de Paris.

La musique transcendante ici est celle des hôpitaux. Il y en a quatre, tous composés de filles bâtardes ou orphelines, et de celles que leurs parents ne sont pas en état d'élever. Elles sont élevées aux dépens de l'Etat, et on les exerce uniquement à exceller dans la musique. Aussi chantent-elles comme des anges, et jouent du violon, de la flate, de l'orgue, du hautbois, du violoncelle, du basson; bref, il n'y a si gros instrument qui puisse leur faire peur. Elles sont cloîtrées en façon de religieuses. Ce sont elles seules qui exécutent, et chaque concert est composé d'une quarantaine de filles. Je vous jure qu'il n'y a rien de si plaisant que de voir une jeune et jolie religieuse, en habit blanc, avec un bouquet de grenades sur l'oreille, conduire l'orchestre et battre la mesure avec toute la grầce et la précision imaginables. Leurs voix sont adorables pour la tournure et la légèreté; car on ne sait ici ce que c'est que rondeur et sons filés à la française. La Zabetta des Incurables est surtout étonnante par l'étendue de sa voix et les coups d'archet qu'elle a dans le gosier. Pour moi, je ne fais aucun doute qu'elle n'ait avalé le violon de Somis. C'est elle qui enleve tous les suffrages, et ce serait vouloir se faire assommer par la populace que d'égaler quelque autre à elle. Mais, écoutez, mes amis, je crois que personne ne nous entend, et je vous dis à l'oreille que la Margarita des Mendicantila vaut bien, et me plaît davantage.

Celui des quatre hôpitaux on je vais le plus souvent, et où je m'amuse le mieux, c'est l'hôpital de la Piété; c'est aussi le premier pour la perfection des symphonies. Quelle roideur d'exécution! C'est là seulement qu'on entend 'ce premier coup d'archet, si faussement vanté à l'Opéra de Paris. La Chiarretta serait sûrement le premier violon de l'Italie, si l'Anna-Maria des Hospitalettes ne la surpassait encore. J'ai été assez heureux pour entendre cette dernière, qui est si

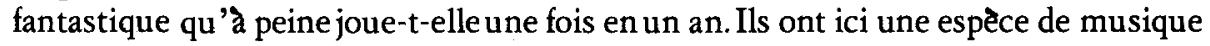
que nous ne connaissons point en France, et qui me paraît plus propre que nulle autre pour le jardin de Bourbonne. Ce sont de grands concertes oủ il n'y a point de violino principale....

Ce n'est qu'ici au monde que l'on peut voir ce que j'ai vu; un homme, ministre et prêtre, dans un spectacle public, en présence de quatre mille personnes, badiner d'une fenêtre a l'autre, avec la plus fameuse catin d'une ville, et se faire donner des coups d'éventail sur le nez. Savez-vous bien que je trouvai un jour à cette princesse un poignard dans sa poche? Elle pretendit que dans sa profession, on était en droit de le porter pour la manutention de la police dans la maison. ${ }^{10 .}$

${ }^{10}$ Le Président de Brosses, ed. par Yves Florence, Mercure de France, 1964, págs. 74-75 y 76-77. 
Por lo demás, las cartas de ambiente veneciano X, XI y XII fechadas 14, 26 y 29 de agosto, dirigidas "A M. de Blancey", "A M. de Quintin" y "A M. de Blancey" respectivamente, demuestran que de Brosses era un libertino observador y culto que divertía a sus amigos borgoñones con agudas y desenfadadas descripciones de su viaje a Italia en 1739. Como en el texto de Brosses, y el de Wright que examinaremos más adelante, la primera escena veneciana de Concierto barroco corresponde al ambiente marino de la ciudad visto desde la perspectiva de un bucentauro, o embarcación a nivel del agua. El viajero francés confirma algunos datos esenciales sobre el carnaval de Venecia, la extensión de las festividades y el despreocupado regocijo que hacia que no hubiera lugar del mundo que lo igualara en la libertad y licencia de sus costumbres. Y tanto las cartas del presidente, como el cuento de Carpentier destacan el placer de los sentidos, lo táctil, visual, olfativo, auditivo y gustativo de los episodios italianos, probablemente porque las inclinaciones del novelista coinciden con la sensualidad del historiador borgoñón. Además es evidente que el escritor cubano comparte con de Brosses la gran admiración por la música barroca y la fina sensibilidad por todas las manifestaciones artísticas de la época. Con su depurado buen gusto, el libertino francés nos asegura que los mejores conciertos de Venecia se hallaban en los hospitales, es testigo del asombroso genio creador de Vivaldi o de la falta de seriedad del público operático italiano. Y por las páginas de este refinado epicureo dieciochesco también desfilan la pintora Rosalba, las huérfanas en sus hábitos blancos, tanto como numerosas apetecibles cortesanas: "Ancilla, Camilla, Faustolla, Zulietta, Angeletta, Catina, Spina, Agatina, et cent mille autre choses en a plus jolies les unes que les autres". "Hallamos el eco de este pasaje en el último capítulo de Concierto barroco cuando el mexicano exclama: "Ya me jode esta ciudad, con sus canales y gondoleros. Ya me he tirado a la Ancilla, la Camilla, la Zulietta, la Angeletta, la Catina, la Faustolla, la Spina, la Agatina, y otras muchas cuyos nombres he olvidado ¡basta! (76-77). Esta irónica y risueña visión de de Brosses está lejos de los muy reales tormentos metafísicos de Rousseau, tal como podemos apreciar de la cita de Les Confessions que reproducimos a continuación.

En écoutant des barcarolles, je trouvais que je n'avais pas oü chanter jusqu'alors, et bientốt je m'engouai tellement de l'opéra, qu'ennuyé de babiller, manger et jouer dans les loges, quand je n'aurais voulu qu'écouter, je me dérobais souvent à la compagnie pour aller d'un autre côté. Là, tout seul, enfermé dans ma loge, je me livrais, malgré la longueur du spectacle, au plaisir d'en jouir à mon aise et jusqu'a la fin....

Une musique à mon gré bien supérieure à celle des opéras, et qui n'a pas sa semblable en Italie ni dans le reste du monde, est celle des scuole. Les scuole sont des maisons de charité établies pour donner l'éducation à de jeunes filles sans bien, et que la république dote ensuite, soit pour le mariage, soit pour le cloître. Parmi les talents qu'on cultive dans les jeunes filles, la musique est au premier rang. Tous les dimanches, a l'église de chacune de ces quatre scuole, on a durant les 
vêpres des motets à grand choeur et en grand orchestre, composés et dirigés par les plus grands maîtres de l'Italie, exécutés dans des tribunes grillées uniquement par des filles dont la plus vieille n'a pas vingt ans. Je n'ai l'idée de rien d'aussi voluptueux, d'aussi touchant que cette musique: les richesses de l'art, le goût exquis des chants, la beauté des voix, la justesse de l'exécution, tout dans ces délicieux concerts concourt à produire une impression qui n'est assurément pas du bon costume, mais dont je doute qu'aucun coeur d'homme soit à l'abri. Jamais Carrio ni moi ne manquions ces vêpres aux Mendicanti, et nous n'étions pas les seuls. L'église était toujours pleine d'amateurs: les acteurs mêmes de l'Opéra venaient se former au vrai goût du chant sur ces excellents modèles. Ce qui me désolait était ces maudites grilles, qui ne laissaient passer que des sons, et me cachaient les anges de beauté dont ils étaient dignes. Je ne parlais d'autre chose. Un jour que j'en parlais chez $M$. Le Blond: Si vous êtes si curieux, me dit-il, de voir ces petites filles, il est aisé de vous contenter. Je suis un des administrateurs de la maison. Je veux vous y donner à goûter avec elles. Je ne le laissai pas en repos qu'il ne m'eût tenu parole. En entrant dans le salon qui renfermätt ces beautés si convoitées, je sentis un frémissement d'amour que je n'avais jamais éprouvé. M. Le Blond me présenta l'une après l'autre ces chanteuses célèbres, dont la voix et le nom étaient tout ce qui m'était connu. Venez, Sophie... Elle était horrible. Venez, Cattina... Elle était borgne. Venez, Bettina... La petite vérole l'avait défigurée. Presque pas une n'était sans quelque notable défaut. Le bourreau riait de ma cruelle surprise. Deux au trois cependant me parurent passables: elles ne chantaient que dans les choeurs. J'étais désolé. Durant le goûter on les agaça; elles s'égayèrent. La laideur n'exclut pas les grâces; je leur en trouvai. Je me disais: On ne chante pas ainsi sans âme; elles en ont. Enfin ma façon de les voir changea si bien, que je sortis presque amoureux de tous ces laiderons. J'osais à peine retourner à leurs vêpres. J'eus de quoi me rassurer. Je continuai de trouver leurs chants délicieux, et leurs voix fardaient si bien leurs visages, que tant qu'elles chantaient je m'obstinais, en dépit de mes yeux, à les trouver belles. ${ }^{12}$

Por lo que acabamos de ver, es evidente que si bien Rousseau compartía con de Brosses su alta opinión sobre la música de los hospitales o "scuole", la visión de las jóvenes huérfanas es más desengañada que la de su coterráneo y posiblemente más cerca de la realidad. Pero tanto el texto de Rousseau, de Brosses como el de Wright coinciden en el mal comportamiento del público italiano que bromea, come, bebe y escupe ruidosamente durante los espectáculos. De las escenas descritas por los viajeros franceses y el inglés, a las fornicaciones en los palcos durante la ópera Agripina mencionada por Carpentier, no hay más que un paso. Veamos ahora algunos de los pasajes destacados del texto de Wright.

There are in Venice four of thefe female hofpitals; this of the Incurabile, the

12 jean Jacques Rousseau, Les Confessions, Livre septieme, Paris: Editions Garniers Frères, 6 Rue de SaintsPeres, págs. 370-371, y 372-373. 
Pieta, Ofpitalletto, and the Mendicanti. Infants are receiv'd into thefe hofpitals; into the Incurabile (originally deftin'd to another ufe) not without a fum given with them; into the Pieta, and the other two, as I take it, without any.

Thofe who would choole for a wife one that has not been acquainted with the world, go to thefe places to look for'em; and they generally take all the care they can, they thall be as little acquainted with the world afterwards. Thofe put into the Pietaे are generally baftards. There are a prodigious number of children taken care of in this holpital: they fay they amount fometimes to at leaft fix thoufand; and that before the erection of this charity, multitudes us' $d$ to be found which had been thrown into the canals of the city. Every Sunday and holiday there is a performance of mufick in the chapels of thefe hofpitals, vocal and inftrumental, perform'd by the young women of the place; who are fet in a gallery above, and (tho' not profefs'd) are hid from any diftinct view of thofe below by a lattice of ironwork. The organ-parts, as well as thofe of the other inftruments, are all perform'd by the young women. They have an eunuch for their mafter, and he compofes their mufick. Their performance is furprifingly good; and many excellent voices there are among them: and there is fomewhat ftill more amufing, in that their perfons are conceal'd from view.

There are more theatres in Venice than in any city of Italy that I have heard of: there are feven for operas, befides others for comedies, \&c. There were operas in three of them, when we were there. The theatres are the properties of feveral noblemen. That of S. John Chryfoftom belongs to one of the Grimani-families: and the fame family has likewife two other theatres, S. Samuel, and S. John and S. Paul, the greateft in Venice. The theatres take their names from the neighbouring churches, and tho' they are in general the property of fuch and fuch noblemen, yet others have boxes as their inheritance, purchas' $d$ of the general proprietor of the theatre; and of thefe they keep the keys themfelves. But before you can come at your box, there is fomewhat to be paid (about Is. 6d. Englifh) for entrance into the theatre. There are no open galleries, as in London, but the whole from bottom to top is all divided into boxes, which one with another will contain about fix perfons each. They have a fcandalous cuftom there, of fpitting out of the upper boxes (as well as throwing parings of apples or oranges, \&c. upon the company in the pit, a praEtice frequent enough here,) which they do at random, without any regard where it falls; tho' it fometimes happens upon fome of the beft quality; who tho' they have boxes of their own, will often come into the pit, either for better feeing the company, or fometimes to be nearer the ftage, for the better hearing fome favourite fongs. Indeed as to feeing the company in the Venetian theatres there is not much entertainment in that; for, not a face is to be feen; but the chief amufement is, to find out, through the difguife of the mafque, who fuch and fuch a one is, which thofe that are accuftomed to the place can very readily do. Thofe that make ufe of books to go along with the performance, have commonly wax-candles in their hands; which are frequently put out by favours from above. 
'Tis very ufual there to fee priefts playing in the Orcheftra: the famous Vivaldi (whom they call the Prete roffo) very well known among us by his concertoes, was a topping man among them.

They are very dextrous at managing the machinery of their operas. In one of them Nero prefents Tiridates king of Armenia with a Roman fhow, of which himfelf makes a part. The emperor with the emprefs appear in a triumphal chariot, drawn by an elephant. The head, trunk, and eyes of the great beaft move as if alive, and Tiridates believe he is fo. When, all of a fudden, as foon as the emperor and emprefs are difmounted and have taken their feats, the triumphal chariot is transform'd into an amphitheatre, and fill'd with fpectators. The elephant falls all in pieces, and out of his belly come a great number of Gladiators, arm'd with bucklers, which were fo many parts of the elephant's fides, fo that he feems in a moment to be transform'd into a company of arm'd men, who make a fkirmifh, all in time to the mufick. ${ }^{13}$

En el prólogo el autor anglosajón se queja de los piadosos fraudes religiosos perpetrados por una casta de sacerdotes que, según este meticuloso observador de la realidad italiana, controlaba las almas del pueblo. En su afán de anotar las costumbres que escandalizaron su sensibilidad protestante, nos revela la austeridad de su carácter. Sin embargo es el viajero que mejor describe las pinturas y objetos de arte tan estimados por la adinerada burguesía y nobleza inglesa. Y también acaba siendo el testigo que proporciona el mayor número de detalles técnicos sobre el teatro de la época. Carpentier aludirá en su relato a los escenarios móviles, decorados, ingenios mecánicos utilizados por los tramoyistas venecianos en el montaje de sus deslumbrantes representaciones. Además Wright suministra datos sobre los comediantes, las costumbres del carnaval, y el animado juego de los festivales públicos. Así y todo, el viajero inglés carece del depurado buen gusto del historiador borgoñón y nunca consigue desprenderse del extrañamiento que le inspira la exótica sociedad de Venecia. Esto se hace patente en la manera de recrearse con los detalles sobre el rito de circuncisión en el ghetto, los comentarios sobre las orejas grotescas de algunos venecianos, las dramáticas referencias al todopoderoso "Consejo de los Diez" y las mórbidas ejecuciones de la "camerotta".

Para encerrar este breve cotejo de las fuentes principales de Concierto barroco conviene examinar el libretto de Motezuma de Alvise Giusti, en el que Carpentier basa el capítulo séptimo de su novela. Como a fin de dar mayor verosimilitud a su historia fantástica el escritor cubano retiene en su obra el elenco original de la ópera, incorpora a Concierto barroco los nombres de los solistas que desempeñaron papeles principales. Y el día del estreno del 'drama per música", regido por Vivaldi en 1733, intervinieron en el acto el señor Massimiliano Miler representando Montezuma, la señora Anna Giró desempeñando el papel de Mitrena, la mujer del emperador azteca, Giuseppa Pircher, la

\footnotetext{
${ }^{13}$ Edward Wright, Some Observations made in Travelling through France, Italy Ec in the Years MDCCXX, $M D C C X X I$ and $M D C C X X I I$, in two volumes. The second edition, London: printed for A Millar, in the Strand, MDCCLXIV, págs. 79-80 y 83-84.
} 
virtuosa alemana de Darmstadt interpretando su hija Teutile, y Angiola Zanucchi, una mujer, representando el papel masculino de Ramiro, hermano menor de Cortés. Las vidas personales de estos cantores sirven al criado negro para improvisar un delirante chismorreo de sal muy gruesa, que hace las delicias del lector. Después Carpentier sigue a grandes trazos la trama de la ópera, comentando de paso los momentos principales de los tres actos: atto primo, scena prima y IV, VII, XVI; atto secondo, scena prima y IV, V, VI, XIV; atto terzo, sceno prima, II, IV , V, X, XI y última. Así mismo en los demás, el autor se limita a destacar mediante citas directas del italiano o en traducciones al español, los elementos dramáticos que atraen su atención. E inclusive es evidente que Carpentier muestra una clara preferencia por los pasajes operáticos con doble sentido para el lector de nuestro tiempo. Por ello traduce la queja de Montezuma en el tercer acto, escena X del libretto de Giusti como: "Estrellas, habéis vencido. / Ejemplo soy, ante el mundo, de la inconstancia vuestra./ Rey fui, quien me jacté, de poseer divinos poderes./ Ahora, objeto de escarnio, aprisionado, encadenado, hecho despreciable trofeo de ajena gloria/ sólo serviré para argumento de una futura bistoria" (67). Es decir, la cita concluye precisamente con un resumen de lo que el novelista cubano está haciendo con el libretto del siglo dieciocho en el capítulo séptimo de Concierto barroco. Además, por boca de sus personajes ficticios, Carpentier demuestra una lectura cuidadosa de la ópera tanto como un conocimiento a fondo de la Historia de la conquista de México de A. Solís. El amo y el criado, cada uno a su manera, comentan como el libretto discrepa en algunos puntos fundamentales de la crónica. El mexicano lo hace mediante aclaraciones eruditas que contrastan ambos textos, el negro con crudas observaciones de subido tono sexual. Por ejemplo el amo nota con espanto que Teuhtlil, "el dueño de la tinta en el polvo", general en los ejércitos de Montezuma y embajador a Cortés, en la ópera se ha transformado en una mujer, Teutile. AN comparar burlonamente el libretto de Giusti y la crónica de Solís, Carpentier desdobla su punto de vista ora asumiendo la persona o máscara del indiano, ora la de Vivaldi. Los comentarios finales de Vivaldi, músico y artista como el escritor cubano, vienen a ser toda una defensa de los derechos de la lógica del espectáculo sobre la lógica de la historia, de la ficción sobre la realidad. $O$, como se recalca con una palabrota en la discusión entre los dos protagonistas de la novela: "La Historia nos dice..." -- No me joda con la Historia en materia de teatro. Lo que cuenta aquí es la ilusión poética...' ,' (69). Es decir, Carpentier en Concierto barroco logra con los textos de Rousseau, de Brosses, Wright y el libretto de Giusti, lo que este se propuso con la crónica de Solís, al exponer en el "argomento"' de su "drama per música" las siguientes palabras también aplicables a la elaboración de cualquier gran obra artística: "Tutto ciò, che di vero abbandono, è che di verisimile aggiongo è per adattarmi alla Scena, e perche meno imperfetto, che sia possibile comparisca il presente Drama..." (89). Sobre este fondo veneciano dieciochesco compuesto por los libros de viaje y el libretto que acabamos de comentar, que no ofrecen mayores complicaciones dramáticas de enredo que limiten la libertad de invención, Carpentier ha hilvanado los detalles de Concierto barroco.

Esto nos permite concluir el análisis resumiendo que tal como en otras obras - sobre todo en El reino de este mundo y El siglo de las luces - el novelista cubano construye su relato a base de textos precisos y documentables. En mi opinión Concierto barroco quizás sea la novela más "textual"' de Carpentier, por ello señalamos entre sus principales fuentes 
literarias el Espejo de paciencia de Silvestre Balboa y la entrada en Barcelona del Quijote de Cervantes. A estas obras podemos añadir libros de viaje de fondo veneciano y un libretto de ópera. Tampoco resulta extraño para el lector que conoce El reino de este mundo que, como de costumbre, los textos históricos se transformen a lo largo del relato cobrando un alucinante aire de ficción. Esta implacable documentación inclusive está en función de hacer aun más verosímil la dimensión imaginativa del relato. De ahí que, como Lenormand de Mezy y Ti Noel, anticipaciones lejanas del amo mexicano y el criado negro Filomeno que irrumpen en el escenario dieciochesco en el capítulo inicial, los personajes imaginarios de Concierto barroco sean los que cobran mayor vida. En último análisis, son los únicos que adquieren cierta profundidad y relieve, hasta dominar e imponer el ritmo a la misma realidad, mejor dicho, a protagonistas históricos - Vivaldi, Haendel y Scarlatti - aunque todos ellos se revelan como fantasmas en los últimos tres capítulos. Por lo demás el escritor cubano vuelve a utilizar como en Guerra del tiempo sus conocidos recursos de romper la coherencia cronológica, en sucesivas rupturas que lo remontan a una privilegiada y fija región intemporal. A este fin Carpentier también introduce en su novela los acostumbrados temas de la música, y el arte en general, como mejor manera de dominar y conquistar el tiempo, la decadencia de occidente y la maravillosa realidad americana como alternativa, tanto como la inmutabilidad de la naturaleza humana. El afán de remontar y dominar el tiempo quizás también nos explique la clara preocupación colorista y pictórica como una eterna, obsesiva busca de continuidad, estabilidad y fijeza a fin de inmovilizar a través del arte un mundo amenazado por el perpetuo cambio y desmoronamiento, visión característica de poetas vanguardistas tales como Neruda en Residencia en la tierra y Carrera Andrade en "Morada terrestre", para dar apenas unos ejemplos concretos. La trama de la "Novelle" está elaborada en diversos sistemas cromáticos en que los ocho capítulos adquieren un colorido y tonalidad especiales, de acuerdo con su significación anímica. Por eso el primer capítulo abre y cierra con un "tour de force" plateado, las palabras "de plata", metal emblemático de la riqueza virreinal mexicana, sustituido por una tonalidad amarillenta, simbólica de la epidemia de fiebre que asola La Habana en el segundo. Una ausencia casi absoluta de colorido en el tercer capítulo revela un estado de ánimo apagado, representativo de la pobreza espiritual de un Madrid decadente. Los episodios venecianos del capítulo cuarto, que inicialmente se esbozan en una marina de difuminados tonos de pastel a la manera de Rose Alba Carriera o las acuarelas de Turner, más adelante ceden a un mareo de colores chillones en medio de la viveza y alegria del carnaval. A fin de subrayar su apoteosis sonora por contraste explícito, a través de un concierto grosso celebrado en un convento, se revierte en el quinto capítulo a algunos tonos de simbolismo colorista tradicional, probablemente derivado de un cuadro de Tintoretto. Y, sobre todo, a un juego de luces y sombras tomado de la técnica pictórica del claroscuro de Rembrandt, de acuerdo con el silencioso ambiente nocturno en que se desarrolla el episodio. No creo que sea casual, por tanto, que del sexto capítulo en adelante se utilice en la mayor parte de las escenas que transcurren en el siglo veinte, un sistema cromático que más se parece a la fotografía, la reproducicion gráfica característica de nuestro tiempo. Por el uso predominatne de intensos nuatices de vianco y negro, colores en oposición cromática, se fijan una serie de imágenes fantasmales y deshumanizadas que parecen una copia brillante montada en papel alto contraste. La fija preocupación gráfica y el uso sistemático del color, a veces con 
efectos realistas, a menudo dentro de un esquema simbólico tradicional en la cultura hispánica, y muy frecuentemente de sostenida alegoría colorista, mediante la insistente acumulación de novedosos matices expresivos estáticos, son dos constantes esenciales de la estilistica carpenteriana. Mientras que el principio de esta técnica ligada a estados anímicos ya se remonta a "Oficio de Tinieblas", es fácil reconocer que en Concierto barroco estos mecanismos ya demuestran mayor sutileza e intensidad características de la obra tardía, donde este afán colorista tanto como los otros mecanismos "barrocos" que hemos examinado, se llevan a sus consecuencias últimas.

Mirasierra, Madrid

KLAUS MULLER-BERGH abril de 1975 